Feito Torrez, M.V. El juez Hermes y el logos de lo razonable: Por qué la aplicación silogística del Derecho no es suficiente. Derecho y Ciencias Sociales. Mayo - Octubre 2020. No 23 Pgs 111-124 -ISNN 1852-2971 Instituto de Cultura Jurídica y Maestría en Sociología Jurídica. FCJ y S. UNLP

\title{
El juez Hermes y el logos de lo razonable: Por qué la aplicación silogística del Derecho no es suficiente
}

Judge Hermes and the logos of the reasonable: Why a syllogistic application of the law is not enough

\section{María Victoria Feito Torrez ${ }^{\bullet}$}

\section{Resumen}

La respuesta insatisfactoria que el positivismo jurídico dio al caso de los líderes nazis en los juicios de Núremberg llevó a que la teoría de la interpretación jurídica volviera a trazar su rumbo. Este artículo hace una revisión teórica de las propuestas de dos juristas destacados: Luis Recaséns Siches y François Ost. Estos autores han contribuido a que las nuevas corrientes de interpretación pongan en duda la aplicación estrictamente formal del Derecho para abrirle el paso a la aplicación razonable, más acorde a la creciente complejidad del orden jurídico.

Palabras claves: Logos, racional, razonable, interpretación, Recaséns Siches, François Ost.

\begin{abstract}
The unsatisfactory answer given by Legal Positivisms the case of the nazi leaders after the Nüremberg trials led the Theory of Legal Interpretation to redefine its borders. This work reviews the contributions of two prominent jurists: Luis Recaséns Siches and François Ost, whose works contributed to the new interpretation schools questioning the strictly formal application of the Law and making a way for a reasonable application, more in accordance with the growing complexity of the legal order.
\end{abstract}

Key words: Logos, rational, reasonable, interpretation, Recaséns Siches, François Ost.

- Traductora pública de inglés por la Universidad Nacional de La Plata, con dedicación exclusiva a la traducción jurídica, diplomada en Inglés jurídico de Derechos Humanos e instrumentos internacionales por la Universidad Católica de Cuyo, miembro del Instituto de Filosofía y Teoría General del Derecho del Colegio de Abogados de la ciudad de La Plata, asociada del Centro de Estudios en Derecho y Religión (CEDyR) de la Universidad Adventista del Plata. Contacto: mavi.feitotorrez@gmail.com

Recibido: 1/11/2019. Publicable: 20/4/2020 
Feito Torrez, M.V. El juez Hermes y el logos de lo razonable: Por qué la aplicación silogística del Derecho no es suficiente. Derecho y Ciencias Sociales. Mayo - Octubre 2020. № 23 Pgs 111-124 -ISNN 1852-2971 Instituto de Cultura Jurídica y Maestría en Sociología Jurídica. FCJ y S. UNLP

\title{
El juez Hermes y el logos de lo razonable: Por qué la aplicación silogística del Derecho no es suficiente
}

\author{
María Victoria Feito Torrez
}

Dice el art. 15 primer párrafo de la ley nacional argentina número 24.193 «Trasplantes de órganos y materiales anatómicos»:

Sólo estará permitida la ablación de órganos o materiales anatómicos en vida con fines de trasplante sobre una persona capaz mayor de dieciocho (18) años, quien podrá autorizarla únicamente en caso de que el receptor sea su pariente consanguíneo o por adopción hasta el cuarto grado, o su cónyuge, o una persona que, sin ser su cónyuge, conviva con el donante en relación de tipo conyugal no menos antigua de tres (3) años, en forma inmediata, continua e ininterrumpida. Este lapso se reducirá a dos (2) años si de dicha relación hubieren nacido hijos.

En alguna ciudad medio recóndita del sur de la Argentina, un juez de primera instancia en lo Civil y Comercial recibe un amparo. De la lectura del escrito que lo fundamenta, surge que Alejandro tiene un problema de salud que afecta severamente sus riñones, y que este problema hace que su supervivencia no sea posible a menos que se le efectúe un trasplante de riñón. Alejandro no tiene muchos parientes: no tiene padres ni hijos, nunca se ha casado, su última pareja lo dejó hace un par de años, y los pocos parientes consanguíneos que tiene bien se han negado a donar un riñón, bien se han prestado pero han resultado biológicamente incompatibles.

Lo que Alejandro sí tiene es un amigo desde muchos años, Pedro, que le ha insistido a los médicos para que testeen su compatibilidad como donador. Estos médicos, que conocen muy bien el artículo 15 de la mencionada ley, le han advertido que la norma no permite la donación de órganos entre amigos. Pero como la insistencia de Pedro no cesa, han hecho los análisis necesarios, y de ellos ha surgido que la compatibilidad entre Pedro y Alejandro es alta, y que Alejandro tiene muchas posibilidades de sobrevivir si recibe el riñón de Pedro. A 
Feito Torrez, M.V. El juez Hermes y el logos de lo razonable: Por qué la aplicación silogística del Derecho no es suficiente. Derecho y Ciencias Sociales. Mayo - Octubre 2020. No 23 Pgs 111-124 -ISNN 1852-2971 Instituto de Cultura Jurídica y Maestría en Sociología Jurídica. FCJ y S. UNLP

través del amparo, entonces, Pedro le pide al juez que autorice a los médicos a quitarle un riñón para implantárselo a su buen amigo, Alejandro.

El juez lee los hechos, lee la letra del artículo, y hace el análisis que sigue: ¿Es Pedro su pariente consanguíneo o por adopción hasta el cuarto grado? No. ¿Es, acaso, el cónyuge de Alejandro? No. ¿Es, entonces, alguien con quien Alejandro ha tenido una relación de tipo conyugal no menos antigua de tres años? No. Luego, Pedro no puede donarle un riñón a Alejandro.

El Alejandro de nuestro caso murió unas semanas después. Pedro, su amigo, no encuentra consuelo.

Ahora: olvídese el lector o la lectora de este texto de que es un operador jurídico. Suponga por unos instantes que trabaja en la administración en una empresa mediana, y que tiene un conocimiento del Derecho ajustado a aquello que le han enseñado en el colegio secundario y a lo que ha aprendido en la calle. El domingo por la mañana, con una pava de mate enfrente, lee la historia de Alejandro y Pedro, más o menos bien relatada por el periodista de algún diario. Dejándose guiar tan solo por el más elemental sentido común, ¿qué le comentaría a la persona que vive con usted? ¿Algo del estilo «qué bien este juez, que decisión justa que tomó»? ¿O algo más del estilo «este juez es absurdo»?

Creo que la mayoría de nosotros estaríamos de acuerdo en que la solución dada por el juez es disparatada, pero ¿qué es lo que empuja a tantos de nosotros a hacer esta valoración, si el juez al fin y al cabo sólo aplicó estrictamente la ley? Quien intenta dar una respuesta a esta pregunta es Luis Recaséns Siches ${ }^{1}$.

Recaséns Siches es un precursor la corriente de la teoría de la argumentación. Esto porque, como otros autores dentro de esta corriente (por ejemplo, Robert Alexy, Theodor Viehweg y Chaïm Perelman), Recaséns Siches ejerce un claro rechazo de la lógica formal como único medio de interpretación del Derecho, y de las lógicas analíticas.

\footnotetext{
${ }^{1}$ Es cierto que la obra de Luis Recaséns Siches tuvo su mayor resonancia hace aproximadamente ochenta años, y que la teoría de la argumentación jurídica ha avanzado enormemente desde entonces. Sin embargo, el puntapié inicial que dio en el sentido de la razonabilidad, alejándose del paradigma estrictamente empirista que venía reinando en el mundo del Derecho, sigue teniendo enorme influencia hoy. Una muestra de la perenne relevancia que tiene la obra de Recaséns Siches es el hecho de que sigue estudiándose y enseñándose —a la par de teóricos de la argumentación más actuales - en las Facultades de Derecho de las universidades más importantes del país. Otro tanto puede decirse de François Ost: el texto que este artículo analiza tiene ya algunas décadas, pero continúa estudiándose en institutos de Filosofía del Derecho y en las clases de la Facultad.
} 
Feito Torrez, M.V. El juez Hermes y el logos de lo razonable: Por qué la aplicación silogística del Derecho no es suficiente. Derecho y Ciencias Sociales. Mayo - Octubre 2020. No 23 Pgs 111-124 -ISNN 1852-2971 Instituto de Cultura Jurídica y Maestría en Sociología Jurídica. FCJ y S. UNLP

La corriente de la teoría de la argumentación ha tomado especial importancia en la segunda mitad del siglo XX. Esto no significa que Recaséns Siches haya comenzado a investigar desde esta perspectiva luego de la Segunda Guerra Mundial. Él, de hecho, había comenzado a criticar la aplicación de la lógica formal como medio primario de interpretación jurídica mucho antes, pero sus ideas tomaron fuerza luego de la Segunda Guerra Mundial.

Ocurre que durante el siglo XIX había nacido la corriente del positivismo jurídico. Antes de ella, el derecho había tenido una interpretación fundamentalmente naturalista: hay algunas potestades universales que el Estado reconoce a las personas ${ }^{2}$. No las crea, sino que reconoce su existencia. Entre estas potestades podemos mencionar la libertad, la igualdad, etc. Claro que la extensión del reconocimiento quedaba ceñida al capricho de los soberanos de turno: si el rey (o quien fuera) decidía que, aunque todos los seres humanos nacen libres, en realidad esto se aplicaba a los hombres blancos y europeos, pero no a los hombres negros traídos de África; o si decidía que sólo las personas que profesaran determinada religión podían ser considerados ciudadanos mientras que los demás no, lo que él decía así era. Limitaba o extendía la «universalidad» de estas potestades inherentes. El iusnaturalismo sirvió para justificar los deseos de los poderosos. Dio fundamento a instituciones que hoy nos parecen aberrantes, como la esclavitud, la pena capital, la designación divina de los reyes (y consecuente sujeción silenciosa de los súbditos), etc.

El positivismo jurídico buscó poner un freno a esto. Para esta corriente, Derecho es sólo aquel puesto y creado por el ser humano; la norma escrita. Antes de ella, no hay nada o, al menos, nada jurídicamente relevante. Todos los actos de los seres humanos deben considerarse a la luz de la norma jurídica, y aquellos actos que no estén contemplados por una norma pertenecerán a la esfera de la libertad de la persona. El punto de estas previsiones era dar seguridad jurídica a los individuos, y que las normas (y su interpretación) no quedaran liberadas a los vaivenes de quienes estuvieran en el poder.

Hasta aquí, puede entenderse qué motivaba a los iuspositivistas. Luego de los hechos aberrantes del nazismo, los líderes nazis fueron juzgados en Núremberg, y aquello que algunos juristas (entre ellos, Recaséns Siches) ya venían criticando al positivismo quedó en

\footnotetext{
${ }^{2}$ El iusnaturalismo, como se imaginará el lector o la lectora, en algunos sentidos no ha sido ideológicamente uniforme a lo largo de su historia. En un principio, estas potestades que las autoridades reconocen provenían de algún ser superior de carácter religioso (dioses). Más adelante, se ha discutido de dónde provienen estas facultades: si de cualidades morales de los seres humanos, o de una esencia inherente a ellos, etc. Sin embargo, todas las escuelas iusnaturalistas comparten la idea de que las potestades que la autoridad reconoce son anteriores (y superiores) a la autoridad misma.
} 
Feito Torrez, M.V. El juez Hermes y el logos de lo razonable: Por qué la aplicación silogística del Derecho no es suficiente. Derecho y Ciencias Sociales. Mayo - Octubre 2020. No 23 Pgs 111-124 -ISNN 1852-2971 Instituto de Cultura Jurídica y Maestría en Sociología Jurídica. FCJ y S. UNLP

evidencia. Es que los líderes nazis habían actuado según las leyes; estas leyes habían sido creadas siguiendo los procedimientos de su Constitución, y por las autoridades facultadas por ella. Estas leyes eran, en fin, válidas. Desde una perspectiva iusnaturalista, las leyes eran formalmente válidas, pero no respetaban un contenido esencial: la justicia, y una ley-si es injusta—no es ley.

Los positivistas, por su parte, no reconocen que haya contenidos esenciales previos, por lo que, desde su perspectiva, los líderes nazis no podían ser culpados: se habían sujetado a las leyes válidas y escritas. Sí, los actos que habían llevado a cabo eran aberrantes, horribles, todo lo disvalioso ${ }^{3}$ que uno se pueda imaginar, pero eran legales. Esta respuesta no satisfizo a la comunidad internacional, y contra ella se levantaron movimientos de interpretación a los que se conoce como dritte Weg, o tercera vía. Entre los juristas de estos movimientos, como decía, se encuentra Recaséns Siches.

Para Recaséns Siches, esta forma silogística de interpretar los contenidos del Derecho-que proponían los iuspositivistas, mayormente los de las escuelas formalistas-no sirve. Durante años se había sostenido que la lógica formal o tradicional podía usarse para aplicar el Derecho al caso particular, pasando por alto que tal aplicación - como en el caso de Pedro y Alejandro-puede llevar a resultados sin sentido. Desde una perspectiva formalista, la aplicación del Derecho podría hacerse como un silogismo: hay una premisa mayor, que es la norma jurídica, y una premisa menor, que son los hechos. La aplicación viene a ser la conclusión. Diríamos en nuestro caso:

$((p \rightarrow q) \neg p) \rightarrow \neg q$

Esto es:

Si el donador es pariente consanguíneo o por adopción hasta el cuarto grado, cónyuge o quien tiene una relación conyugal $\rightarrow$ puede donar.

Pedro no es pariente consanguíneo o por adopción hasta el cuarto grado, cónyuge o quien tiene una relación conyugal con Alejandro $\rightarrow$ no puede donar.

\footnotetext{
3 "Disvalioso" es un término que no existe en la lengua española. Al menos, los diccionarios más consultados no lo reconocen. Ocurre que no hay un término que exprese mejor el sentido de ser opuesto al ser valioso.
} 
Feito Torrez, M.V. El juez Hermes y el logos de lo razonable: Por qué la aplicación silogística del Derecho no es suficiente. Derecho y Ciencias Sociales. Mayo - Octubre 2020. No 23 Pgs 111-124 -ISNN 1852-2971 Instituto de Cultura Jurídica y Maestría en Sociología Jurídica. FCJ y S. UNLP

Esta es la forma de razonar de las lógicas duras: cumple o no cumple con una condición. ¿La cumple? Puede seguir. ¿No la cumple? No ha lugar. No importa si no aplicar la norma lleva a un resultado injusto o absurdo. Evidentemente lo que hay es un forzamiento de las estructuras de pensamiento, y esto lleva a que los jueces decidan cosas que no tienen sentido.

Lo que plantea Recaséns Siches deja ver que hay más de un tipo de estructura de pensamiento; que el logos de lo racional no es la única forma de interpretar los contenidos del derecho: el Derecho no consiste solamente en una operación lógica deductiva. Hay, dentro del logos, contenidos racionales y otros que no lo son. Estos otros contenidos, entre ellos el logos de lo razonable o logos de lo humano, no están completamente separados del logos de lo racional: hay interferencias, combinaciones y superposiciones entre ambos.

Todo esto no quiere decir que hay que descartar completamente los contenidos racionales del logos, sino que hay que utilizarlo para aquellas partes del Derecho donde sean más efectivos. A grandes rasgos, el logos de lo racional sirve para estudiar la estructura del Derecho; aquello del Derecho que es a priori: la estructura de la norma jurídica, la conformación del ordenamiento jurídico, las relaciones de unidad y jerarquía entre las normas del sistema, etc. Pero hay una «zona» del Derecho donde este logos de lo racional no es suficiente. No alcanza. No es fácil precisar cuándo y hasta dónde debe emplearse, pero nos damos cuenta de que, cuando su aplicación estricta arroja conclusiones absurdas, debemos utilizar otras lógicas del logos ${ }^{4}$.

En general, estos resultados absurdos o contradictorios surgen al momento de aplicar el logos de lo racional o al contenido de las normas. Esto es porque, distinto de las estructuras, el contenido de las normas y su aplicación al caso concreto requieren que el legislador y el juez recurran a la axiología. Dicho de otra forma: para hacer sus trabajos, el legislador y el juez deben valorar las conductas humanas, y la valoración no es parte del logos de lo

\footnotetext{
${ }^{4}$ Recaséns Siches sostiene que hay un logos compuesto por varias lógicas. La lógica formal es una de ellas, pero hay otras: la lógica de la razón vital, la lógica de la razón histórica, la lógica estimativa, la lógica de la finalidad, etc. Lo que no termina de quedar claro es si a todas las lógicas que no son la racional él las agrupa bajo el rótulo «logos de lo razonable» o si es que — así como el logos de lo racional—el logos de lo razonable es otro más dentro de un gran logos, y además de estos dos hay otros. Me da la impresión de que la primera respuesta es la correcta: pareciera que Recaséns Siches llama «logos de lo racional» a lo que podría llamarse «logos de lo no racional». Me inclino por esta respuesta porque todos los ejemplos de otras lógicas que enlista (las que acabo de mencionar) tienen en común la relación con la experiencia humana y la naturaleza del mundo en el que el ser humano habita, que es - al fin y al cabo - el contenido mismo del logos de lo razonable.
} 
Feito Torrez, M.V. El juez Hermes y el logos de lo razonable: Por qué la aplicación silogística del Derecho no es suficiente. Derecho y Ciencias Sociales. Mayo - Octubre 2020. № 23 Pgs 111-124 -ISNN 1852-2971 Instituto de Cultura Jurídica y Maestría en Sociología Jurídica. FCJ y S. UNLP

racional. Valorar implica que haya grises, que haya zonas de penumbras; el contenido de una norma o su aplicación al caso concreto puede ser más o menos valiosa, más o menos justa, pero rara vez (si alguna) es completamente valiosa, completamente disvaliosa, completamente justa o completamente injusta. El logos de lo racional funciona en blancos y negros; el logos de lo razonable, no.

Para Recaséns Siches es claro que aunque el logos de lo razonable dé lugar a valoraciones, o no se aplique de forma binaria, no es irracional. Cuando la interpretación jurídica encuentra que el método formal no alcanza, «sentimos que hay razones muy importantes, decisivas, para tratar el problema planteado de una manera tal que se haga a un lado aquella lógica tradicional. Ahora bien, si sentimos que hay razones, esto quiere decir que estamos en el campo del logos» $(1956,32)$. Sigue siendo un razonamiento, pero uno distinto del formal.

La pregunta que sigue es, ¿qué conforma el logos de lo razonable? ¿A qué se refiere? Recaséns Siches sostiene que las normas son la conducta humana objetivada: pedazos de la vida humana objetivada. El contenido del logos de lo razonable es entonces aquello que hace a la vida del ser humano y al mundo en el que él habita. Se trata de los pensamientos humanos, según las necesidades prácticas de su vida social.

Por supuesto, Recaséns fue grandemente criticado. Es muy difícil determinar a qué llamamos «la vida humana», «los pensamientos humanos», «las necesidades prácticas de la vida social». Son todos términos vagos, y vagos de una vaguedad insoportable. Entonces, el planteo de Recaséns es atractivo, pero sumamente difícil de pautar. Es casi imposible determinar, mediante normas, cómo deberán hacer los legisladores y los jueces para decidir teniendo en cuenta estos elementos y las valoraciones que de ellos pueden hacerse. De hecho, en nuestro ordenamiento jurídico, el Código Civil y Comercial argentino ha dado a los jueces una escueta pauta en el artículo 3, según el cual las sentencias deben estar «razonablemente fundadas». No es casualidad que el legislador no haya dicho «racionalmente fundadas», sino que se haya referido directamente al logos de lo razonable. Es que el legislador ha tomado un lenguaje propio de las corrientes interpretativas.

Otra crítica que cabe hacerle a Recaséns Siches es que aquello a lo que él llama «aplicación racional» $\mathrm{o}$ «aplicación deductiva» de las normas ${ }^{5}$ sería rechazado por las ciencias formales.

\footnotetext{
${ }^{5}$ Me refiero a esta noción de que si cumple con una condición puede aplicársele la norma, pero si no cumple, no. Recaséns Siches trae de Radbruch un ejemplo muy ilustrativo sobre una estación de trenes donde se ha colocado un cartel que dice «prohibido entrar con perros». El guarda, entonces, prohíbe la entrada de perros, aún de los pequeños, pero permite la entrada de un oso.
} 
Feito Torrez, M.V. El juez Hermes y el logos de lo razonable: Por qué la aplicación silogística del Derecho no es suficiente. Derecho y Ciencias Sociales. Mayo - Octubre 2020. No 23 Pgs 111-124 -ISNN 1852-2971 Instituto de Cultura Jurídica y Maestría en Sociología Jurídica. FCJ y S. UNLP

Mencionaba más arriba la fórmula $((\mathrm{p} \rightarrow \mathrm{q}) \neg \mathrm{p}) \rightarrow \neg \mathrm{q}$. Mencioné también que hay un forzamiento de las estructuras del pensamiento. Y así es: el forzamiento consiste en convencer al interlocutor o interlocutora de que este razonamiento es válido. En realidad, esta fórmula no describe un razonamiento válido, sino una falacia conocida como «negación del antecedente». La forma lógica correcta sería:

$((p \rightarrow q) p) \rightarrow q$

O, en el ejemplo de Alejandro y Pedro:

Si es un pariente consanguíneo o por adopción hasta el cuarto grado del receptor, o su cónyuge, o una persona que, sin ser su cónyuge, conviva con el donante en relación de tipo conyugal no menos antigua de tres (3) años, en forma inmediata, continua e ininterrumpida $\rightarrow$ puede donar.

Pedro es cónyuge de Alejandro $\rightarrow$ Pedro puede donarle a Alejandro.

El forzamiento consiste en hacer pasar una falacia por un silogismo bien formado, y lograr-de hecho- convencer a otros de su corrección.

Imagino que si Recaséns Siches estuviera vivo respondería que él sabe bien que esto no es un silogismo válido sino una falacia, pero que no por eso deja de ser verdad que muchos jueces siguen este razonamiento para aplicar el derecho, y que lo que a él le interesa no es tanto hacer un tratado de lógica formal, sino describir un razonamiento que se utiliza frecuentemente en la aplicación del Derecho. Lamentablemente, como puede corroborarse con la lectura de algunos pocos expedientes, esto es cierto.

Aunque la propuesta de Recaséns Siches puede criticarse, no puede negarse que ha sido el primer paso en esta nueva dirección que ha tomado la interpretación jurídica. Recaséns Siches plantó esta primera semilla, y otros autores han continuado su línea de pensamiento. 
Feito Torrez, M.V. El juez Hermes y el logos de lo razonable: Por qué la aplicación silogística del Derecho no es suficiente. Derecho y Ciencias Sociales. Mayo - Octubre 2020. No 23 Pgs 111-124 -ISNN 1852-2971 Instituto de Cultura Jurídica y Maestría en Sociología Jurídica. FCJ y S. UNLP

Entre estos autores podemos mencionar a François $\mathrm{Ost}^{6}$. En su artículo «Júpiter, Hércules, Hermes: tres modelos de juez», Ost comienza por referirse a un juez asimilable a la figura de Júpiter. Este juez se encuentra en la cumbre de una pirámide o código, y desde esta cumbre «guía» la deducción de las normas inferiores. El orden jurídico que sostiene a este Juez está organizado por gradas, de manera lógica, a partir de una norma superior supuesta: la famosa norma hipotético-fundamental de Kelsen, o la regla de reconocimiento de Hart. El sistema conlleva un monismo ideológico que toma la forma dominante de la ley, una centralización administrativa que culmina con la figura del soberano (en los términos de Austin). La racionalidad que motiva al ordenamiento es deductiva y lineal, y hace especial énfasis en la racionalidad del legislador (aquella que evita los problemas sistemáticos tales como la falta de cohesión o la redundancia). Por ende, se hace énfasis en su capacidad de abstraer las conductas humanas en normas generales, perfectamente aplicables a todas las situaciones particulares.

Es evidente que este modelo de juez se mueve en la esfera racional del logos. Las características descriptas por Ost responden a todo aquello que es a priori dentro del ordenamiento: la jerarquía, la linealidad, la aplicación deductiva de una norma general a un caso particular, etc. Pierre Bordieu $(1986,42)$ se refiere a la simplicidad y comunicabilidad de la codificación. Lo que cabe preguntarse es si en la creciente complejidad de la sociedad (y del Derecho) puede seguir insistiéndose con la simplificación de estructuras y contenidos y, de ser así, si esto no causará una crisis. En la opinión de Ost, es esto lo que causó la crisis del modelo jupiterino.

Por otra parte, Ost describe un segundo modelo de juez que identifica con Hércules. Hércules buscaba redimir su falta haciendo grandes esfuerzos en grandes actos. De la misma forma, el juez herculino es aquél que entiende en todas las situaciones, por más diversas que sean, atendiendo no tanto a la norma general, o más bien, muy poco a la norma general, pero mucho al caso particular. Dentro de esta concepción del Derecho, el Derecho no es un conjunto de reglas deducidas, sistematizadas, etc. sino un complejo de comportamientos de las autoridades jurídicas.

\footnotetext{
${ }^{6}$ Ost y Recaséns Siches hacen énfasis en lo que considero ser dos caras de una moneda: aquél se refiere a la creación social de sentido, y este a la argumentación. Llamo a esto dos caras de una moneda porque la argumentación no es una actividad social que flota en el aire fuera del alcance de las personas y sin tocar a la sociedad, sino que el lenguaje — a través de herramientas como la argumentación de los agentes jurídicos—crea la realidad social, y a su vez la realidad social afecta a la argumentación.
} 
Feito Torrez, M.V. El juez Hermes y el logos de lo razonable: Por qué la aplicación silogística del Derecho no es suficiente. Derecho y Ciencias Sociales. Mayo - Octubre 2020. No 23 Pgs 111-124 -ISNN 1852-2971 Instituto de Cultura Jurídica y Maestría en Sociología Jurídica. FCJ y S. UNLP

Al revés que en el caso jupiterino, aquí las decisiones no surgen de las normas sino al revés: las normas surgen de las decisiones de los jueces. Y el material que usan los jueces para tomar estas decisiones no es la norma sino manifestaciones esporádicas de las voluntades de los jueces: las decisiones judiciales. De esta forma, la norma se convierte en un instrumento flexible, adaptable al caso particular: no hay un proceso deductivo de la norma general al caso particular, sino un proceso inductivo del caso particular a la norma general ${ }^{7}$. En pos de esta flexibilidad, ante el caso particular, debe someterse la pretensión de coherencia lógica, porque - al fin y al cabo-lo que busca el juez es llegar a la resolución del caso: a un resultado práctico.

El quid de la cuestión es que no es la lógica la que va a ayudar al juez a llegar a este resultado, sino la economía, la contabilidad, la criminalística, la medicina, etc. Puesto en los términos de Recaséns Siches, el juez herculino, para llegar a una decisión, no va a echar mano de lo racional del logos, sino de todo lo demás que forma parte del logos. Donde el juez jupiterino utiliza la linealidad jerárquica, el juez herculino utilizará la circularidad (Ost de hecho se refiere a la «circularidad viciosa $\left.{ }^{8} »\right)$, y allí donde el juez jupiterino aplicaría el principio de clausura, el juez herculino aplicará la más radical hermenéutica ${ }^{9}$, la más libre interpretación creativa.

Si bien no lo dice explícitamente, Ost parece apuntar a que ambos jueces, Júpiter y Hércules, cometen los mismos errores. Son dos extremos de un continuo, y como extremos que son, reflejan como en espejo los defectos del otro. Uno de estos jueces apela solamente (o mayormente, o principalmente) al logos de lo racional, mientras que el otro rechaza esta porción del logos y apela solamente al logos de lo humano. La solución, para él, no es buscar un Derecho que meramente mezcle elementos de ambos. La solución es una tercera opción (casi como una dritte Weg), a la que llama el juez Hermes.

Aquí viene lo interesante de la propuesta de Ost: el juez Hermes no intenta simplificar el Derecho. Sabe que el Derecho ha ido creciendo en la complejidad que caracteriza a la

\footnotetext{
${ }^{7}$ Ost contrapone ambos órdenes jurídicos en estos términos. Debe notarse, sin embargo, que en el proceso de interpretación y aplicación del Derecho no hay solo razonamientos deductivos o inductivos, sino otros tipos de razonamientos, como por ejemplo los abductivos.

${ }^{8}$ El autor no aclara por qué califica de «viciosa» a la circularidad del método herculino. Entiendo que la circularidad está dada porque las nuevas decisiones de los jueces «corroboran» (en términos popperianos) las decisiones anteriores (que motivaron las nuevas), y esto crea un círculo de decisiones del cual es difícil salir. Cuando hay una excepción a esta circularidad, la llamamos «leading case».

9 «Hermenéutica» es el término utilizado por Ost, o al menos por la traductora. Creo que aquí sería más adecuado hablar de heurística, porque lo que podría contraponerse con lo lineal del principio de clausura es la aplicación creativa del juez, y esto guarda más relación con la heurística que con la hermenéutica.
} 
Feito Torrez, M.V. El juez Hermes y el logos de lo razonable: Por qué la aplicación silogística del Derecho no es suficiente. Derecho y Ciencias Sociales. Mayo - Octubre 2020. No 23 Pgs 111-124 -ISNN 1852-2971 Instituto de Cultura Jurídica y Maestría en Sociología Jurídica. FCJ y S. UNLP

posmodernidad, y busca formas de coordinar esta complejidad, no de simplificarla. Entonces, propone ver al Derecho no como una pirámide (como el juez jupiterino), ni como un embudo (como el juez herculino), sino como una red. Esta red no es aleatoria, sino que conserva relaciones de jerarquía. Esto hace que no sea totalmente imprevisible, pero que al mismo tiempo sea flexible. Asimismo, la figura de Hermes no se reduce solamente al juez, sino que abarca a todos los operadores jurídicos, porque no solo los jueces interpretan el Derecho, sino que todos los que participan en los procesos judiciales lo hacen.

Hasta aquí, daría la sensación de que el orden que contiene a Hermes es una combinación de los otros dos. Ost sostiene que en realidad lo que hay es una operación dialéctica entre el orden jupiterino y el herculino: hay una articulación, un «ida y vuelta» entre la norma y los hechos del caso particular, la deducción y la inducción, la letra y el espíritu de la ley, la estructura y los valores, etc. Hay, en definitiva, y como decía Recaséns Siches, «interferencias, combinaciones y superposiciones» entre los contenidos del logos de lo racional y los contenidos del logos de lo razonable. Esta dialéctica, dice Ost, se refleja en un juego cuyos roles (los de los operadores jurídicos) y réplicas no están enteramente programados.

En cierta medida, sí; hay una cierta jerarquía, particularmente dentro de las instituciones; hay una cierta reglamentación, pero no es completa. Porque si todo el orden jurídico estuviera reglado, si no hubiera espacio para el azar, no habría juego. Y por el contrario, si todo fuera azar, y no hubiera previsibilidad alguna, tampoco habría juego. Son los dos extremos que Hermes intenta vincular. Son los dos contenidos del logos entre los cuales Recaséns Siches veía difícil trazar una línea divisoria.

Ost sostiene que hay sectores del orden jurídico para los cuales lo más aconsejable es hacer especial énfasis en el modelo jupiterino. En este sentido, menciona particularmente el aspecto procesal: las normas procesales. Para él, la racionalidad aplicada al proceso judicial tiene un doble mérito: descalificar «la violencia que intentaría imponer su punto de vista por la fuerza y a la buena conciencia mayoritaria que arriesga todo por imponer sus opiniones en nombre del pretendido consenso ${ }^{10} \mathrm{y}$ «mostrar el lazo fundamental que se establece entre el respeto a los procedimientos y los derechos fundamentales».

\footnotetext{
${ }^{10}$ Es curioso que ambos autores, Ost y Recaséns Siches, sean críticos de la «voluntad general» fuertemente defendida por Rousseau en su Contrato social. He pensado mucho en este asunto y he llegado a la conclusión de que el disenso entre los autores contemporáneos y las propuestas de Rousseau radica en el significado de las palabras «mayoría» $\mathrm{y}$ «minoría». Es decir, que llaman «minoría» y «mayoría» a distintas cosas. En el contexto
} 
Feito Torrez, M.V. El juez Hermes y el logos de lo razonable: Por qué la aplicación silogística del Derecho no es suficiente. Derecho y Ciencias Sociales. Mayo - Octubre 2020. No 23 Pgs 111-124 -ISNN 1852-2971 Instituto de Cultura Jurídica y Maestría en Sociología Jurídica. FCJ y S. UNLP

Respecto de la primera, su mérito radica en que, al haber normas claras en lo procedimental, la división social entre quien acusa y quien se defiende se vuelve clara, previsible. Esto permite que ambas puedan hacer sus mejores defensas, porque sus roles son claros, y también lo es el del juez. En síntesis, las vías argumentativas para la negociación están claras para todas las partes, y no dependen enteramente de la voluntad de las otras: están constreñidas a las vías racionales de discusión.

Respecto de la segunda, el punto es que los contenidos de los derechos fundamentales no son completamente blandos (soft). Al estar-en los términos de Garzón Valdéz-en un «coto vedado», los derechos fundamentales no quedan al arbitrio del intérprete jurídico ni de la capacidad de modificación del legislador. No son parte ni únicamente del logos de lo racional ni únicamente del logos de lo razonable, sino que están en una superposición de ambos. En este sentido, una gran cantidad de lo que hace al logos de lo racional de los derechos fundamentales es el procedimiento por el cual se defienden. Esta es la relación que guarda con el primer mérito.

Ost sostiene también que hay sectores del orden jurídico para los cuales lo más aconsejable es hacer especial énfasis en el modelo herculino. Aquí menciona algunos valores que podemos identificar con principios generales del Derecho ${ }^{11}$, tales como la democracia, el favor por los más débiles, e incluso aquello del ordenamiento que pone responsabilidades sobre los individuos (por ejemplo, el bien colectivo por sobre el bien individual). Es claro que, para determinar cómo aplicar estos principios, no alcanza con echar mano al logos de lo racional, porque justamente lo que compone estos aspectos del ordenamiento es la experiencia humana a la que Recaséns Siches hacía referencia.

Lo que resta por decir es que las críticas que se le hicieron a Recaséns Siches pueden hacérsele también a Ost: ¿Cómo sabemos cómo es la «red» del orden de Hermes? ¿Cómo

de la Revolución Francesa, y un poco como reacción de hartazgo contra la monarquía que hasta entonces imperaba, Rousseau llama «mayoría» simplemente al mayor número de voluntades, y «minoría» a la voluntad de un grupo pequeño de personas. En la actualidad, aquello que distinguimos como «mayoría» o «minoría» no tiene tanta relación con el número de personas que conforma el grupo, sino con el poder social que esas personas ejerzan. Para Rousseau, la minoría era la que ejercía la mayor parte del poder social. Para nosotros es al revés: «minoría» es casi un sinónimo de «desprovistos de poder social». Visto así se entiende el porqué del rechazo de Rousseau a las minorías y la exaltación de la voluntad general, y el porqué de la defensa a las minorías que nace con los Derechos Humanos.

${ }^{11}$ Los principios que identifico con aquello que Dworkin llama estándares de moralidad o justicia, los quenormalmente - emanan de la norma superior o de la Constitución. No me refiero a aquellos que se deducen (o abducen) de las normas de una rama del Derecho; los que generalmente llamamos «principios jurídicos». Creo que aquello a lo que Ost hace referencia no podría identificarse con, por ejemplo, el principio de la administración transparente de las finanzas en el derecho administrativo, o el principio dispositivo del derecho procesal. 
Feito Torrez, M.V. El juez Hermes y el logos de lo razonable: Por qué la aplicación silogística del Derecho no es suficiente. Derecho y Ciencias Sociales. Mayo - Octubre 2020. No 23 Pgs 111-124 -ISNN 1852-2971 Instituto de Cultura Jurídica y Maestría en Sociología Jurídica. FCJ y S. UNLP

sabemos qué partes de esta red son previsibles o racionales y qué partes quedan al arbitrio de lo que los operadores jurídicos encuentran razonable? ¿Quién escribe las reglas del «juego» de interacción entre el modelo jupiterino y el herculino? Todo esto es también de una vaguedad insoportable. Sin embargo, esto no justifica descartarlo completamente: así como lo propuesto por Recaséns Siches, es sin duda un paso más hacia la comprensión de este objeto tan complejo que llamamos «Derecho».

La primera lección que podemos sacar del análisis de las ideas de estos autores es que una aplicación silogística del Derecho efectivamente no alcanza para llevar la norma general al caso particular. Cuando decimos que los jueces no pueden ser autómatas que meramente repitan las palabras de la ley estamos diciendo precisamente esto: que una aplicación binaria de las normas puede llevar a absurdos difíciles - si no imposibles-de ulterior reparación. Una gran parte de las justicia del caso particular es la interpretación razonable del juez (y de los operadores jurídicos que intervienen); es el echar mano al logos de lo razonable, y hacer la labor del juez Hermes. Es, en fin, la experiencia del mundo que hace que jueces y operadores sean seres humanos aptos para ver a los justiciables no como enigmas abstractos que resolver sino como seres iguales a ellos.

Una segunda lección es que nuestro entendimiento del Derecho no es acabado. Es mucho lo que se ha escrito, y es mucho lo que se ha escrito sobre lo que se ha escrito (como, por ejemplo, este texto), pero la creciente vastedad del Derecho supera lo que los juristas pueden escribir. Cada autor, cada texto, aporta una novedad: Recaséns Siches nos dejó el ya no poder aceptar con tranquilidad la mera aplicación formal de las normas; Ost nos deja la expansión de la interacción entre los componentes del logos no sólo en cuanto al contenido del Derecho sino en cada operador, cada acto, cada parte.

Y si el Derecho se complejiza, crece y expande, y en consecuencia la literatura jurídica avanza, crece y se expande, a nosotros - como operadores jurídicos-nos toca ir detrás de ellos: leer un poco cada día, estudiar un poco cada día, aprender un poco cada día, sacarnos cada día las anteojeras. Porque este avance no espera a quienes se quedan atrás. 
Feito Torrez, M.V. El juez Hermes y el logos de lo razonable: Por qué la aplicación silogística del Derecho no es suficiente. Derecho y Ciencias Sociales. Mayo - Octubre 2020. № 23 Pgs 111-124 -ISNN 1852-2971 Instituto de Cultura Jurídica y Maestría en Sociología Jurídica. FCJ y S. UNLP

\section{Bibliografía}

Atienza, M. Las razones del Derecho. Teorías de la argumentación jurídica. México : IIJUNAM (2003).

Bordieu, $\mathrm{P}$ «Habitus, code et codification», en Actes de la recherche en sciences sociales, número 64, septiembre de 1986, p. 42.

Copi, I. Introducción a la lógica (pp. 17-58). Buenos Aires: Editorial Universitaria de Buenos Aires (1967).

Fairclough, N. Language and Power. London: Longman (2001)

Garzón Valdéz, E. “Algo más acerca del «coto vedado»”. Doxa. N. 06 (1989), pp. 209-213.

Disponible en: https://doxa.ua.es/article/view/1989-n6-algo-mas-acerca-del-coto-vedado

Gibbons, J. (editor), Language and the Law. London: Rutledge (1994).

Ley nacional 24.193 (1993), consultada el 15/10/2019, disponible en http://servicios.infoleg.gob.ar/infolegInternet/anexos/0-4999/591/texact.htm

Ost, François. “Júpiter, Hércules, Hermes: tres modelos de juez”. Doxa. N. 14 (1993), pp. 169-194. Disponible en: https://doxa.ua.es/article/view/1993-n14-jupiter-herculeshermes-tres-modelos-de-juez

Recaséns Siches, L. P. A. (1956) «El logos de "lo razonable" como base para la interpretación jurídica», Diánoia, vol. 2, №2, p.32.

Tinant, E. L. "La interpretación en el derecho”, La Ley, 1982-B, 993 (1982). 